\section{The vaccine-autism controversy}

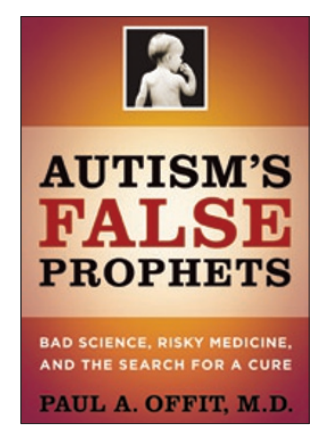

\section{Autism's False Prophets: Bad Science, Risky Medicine, and the Search for a Cure}

Paul A. Offit

Columbia University Press, 2008

328 pp., hardcover, $\$ 24.95$

ISBN: 0231146361

\section{Reviewed by Daniel Geschwind}

Autism is a devastating developmental neuropsychiatric disorder whose symptoms emerge during the first three years of life. Although recent genetic studies have provided major advances in our understanding of autism's etiologies in up to $10 \%$ of cases, the causes of most cases are not known. This has spawned an industry around speculative causes and cures and years of misguided notions, including the early assertion that cold, 'refrigerator' mothers were contributory. Because children receive vaccinations during the period of symptom emergence, there is the potential for association between the time of vaccination and the appearance of autistic symptoms.

Thus, it was a very reasonable question for parents and researchers to ask whether there is a true association, or even a causal relationship, between vaccines and the disorder. In fact, the same issue was raised more than a decade ago with regards to a rare syndrome known as infantile spasms. After a few epidemiological studies, and a US Institute of Medicine report, the weight of the scientific evidence was clearly against any relationship between infantile spasms and vaccination, and the issue was appropriately dropped, permitting the field to move on.

With regard to autism, more than a dozen epidemiological studies in several countries have been conducted, each asking whether autism is associated with vaccines, and all have been negative. This scientific evidence has put the issue of whether vaccines have led to an autism epidemic to rest in biomedical circles. Yet, the controversy regarding the vaccine-autism link still persists in the public eye. The question for many, including me as a medical scientist involved in autism research, is why?

This is the question that Paul Offit addresses in his gripping book Autism's False Prophets. In it, Offit, himself a leading figure in infectious disease research and vaccines and the parent of an autistic child, paints an eloquent picture of the social context in which the vaccine-autism controversy developed and persists. Despite the difficulties that his position as a "parent for vaccines" has caused him, including death threats, Offit's narrative is not bitter or maudlin. Rather, Autism's False Prophets reads like a legal thriller. It is rapidly paced, starting with the author's own childhood and poignant descriptions of his motivations for his career choice and ending with the media and America's

Daniel Geschwind is at the David Geffen School of Medicine at University of

California Los Angeles, Los Angeles, California, USA.

e-mail: dhg@ucla.edu celebrity obsession, which he portrays as having had a dominant role in clouding the truth.

Offit takes the reader from claim to claim, detailing the personalities and data supposedly behind each vaccine-autism association, starting with the measles-mumps-rubella vaccine and continuing with the diphtheria-pertussis-tetanus vaccine that contained thimerosal, a mercury derivative, as a preservative. Through vignettes containing quotations from politicians and celebrities, and backed by opinions from crusading parents and physicians, Offit weaves a compelling narrative. Herein lies the real human interest: how, in some cases, physicians and scientists on the fringes of their fields have managed to keep the controversy alive while at the same time providing potentially dangerous therapies, such as chelation, despite no evidence supporting the efficacy of these therapies.

But this book is not just about the politics and scandals associated with science and its intersection with public policy. It also chronicles, in a compelling fashion, the advocacy groups, public relations efforts and legal efforts that have often partnered, certainly in some cases as innocents, with rogue scientists in this endeavor to link autism with vaccines. As the title of the book suggests, in some cases, the belief in the causal role of vaccines is an issue of faith; in others, the motives may be less lofty.

One might consider it ironic that this book does not particularly deal with the 'hard' science itself - it does not go into depth describing the science that has been consistently negative regarding any real connection between vaccines and autism. Offit does not describe any of the more than one dozen negative studies in detail. Rather, he chronicles in a careful, detailed timeline the many factors keeping the vaccine-autism controversy alive, from the sordid scientific frauds that have been perpetrated in the attempt to keep this controversy alive to simple methodological misconceptions and the personalities and potential motivations of many of the key players. This social context is less dry than science and is, of course, what makes the book such an entertaining read.

This is an important book from a brave and articulate champion of the truth, as best we can know it. Autism's False Prophets highlights the frightening manner in which the media's lack of interest in the truth, coupled with the public's distrust of science, has created a volatile mix of falsehoods and controversy. In fact, many fascinating questions are raised, such as the role of politicians and celebrities in fanning the flames of controversy, and why, despite being highly educated public servants with the public good at heart, these politicians have a distrust of science and the biomedical profession.

Tragically, this false controversy has the potential to cause real harm, as Offit warns. Lack of herd immunity caused by a reduction in childhood vaccination on the basis of fears of autism has already led to measles outbreaks, resulting in dozens of hospitalizations and deaths. Furthermore, this controversy diverts attention from some of the real issues - is the rate of autism increasing, and, if so, what is causing this increase? Although vaccines can induce rare adverse reactions, they are not responsible for autism in the population in any sense, so it is up to researchers to identify what might be behind a potential increase, for the sake of our children and our communities. Diverting attention from this and from identifying the genetic and other environmental contributors to autism wastes money and time, which, unfortunately, passes quickly. Hopefully, so will this issue, allowing the field to move on. 